\title{
The Effect of Loading on The Generator Voltage on The Pico-Hydro Power Plant: Experimental Study
}

\author{
Azhar $^{1}$, Muhammad Kamal ${ }^{1}$, and Subhan ${ }^{1}$ \\ \{azhar@pnl.ac.id\} \\ ${ }^{1}$ Department of Electrical Engineering, Politeknik Negeri Lhokseumawe, Lhokseumawe, Indonesia
}

\begin{abstract}
Experimental study: generator loading at a $1 \mathrm{KVA}, 400 \mathrm{Volt}, 50 \mathrm{~Hz}$, $1500 \mathrm{rpm}$ power plant shows that the frequency and voltage are down slowly due to the inability of the spin of the water turbine to compensate the nominal rotation of the generator. Impulsive and rapid load changes can also cause the voltage drop in the generator. Voltage instability will affect the quality of apparent power generator generated. In this study, the generator is driven by a water turbine at $1500 \mathrm{rpm}$ and loaded $1 \mathrm{~kW}$. The excitation system generator is a self-excitation system. Voltage excitation field 18 Volt generator and excitation current $350 \mathrm{~mA}$. The result of simulation of generator loading at 414.3-1183.2 VA, generator voltage decreases slowly from 399-380 Volt. Generic power generated by generator shows a linear increase of 138.1-394.4 VA. If a load of the generator is raised up to $1183.3 \mathrm{VA}$, the generator voltage falls to 380 Volts. The real power produced below the nominal is $394.4 \mathrm{VA}$ and the load current is 0.6 Ampere.
\end{abstract}

Keywords: The Pico-hydropower plant, The generator voltage, Self-excitation and The apparent power.

\section{INTRODUCTION}

The quality of electric power generated by the power plant must have at least; frequency and voltage in stable condition. At each power plant, the frequency and voltage stability are obtained directly from the generator spin regulation. The nominal spin of a generator is generally $1500 \mathrm{rpm}$. The inability of the prime mover of the generator to compensate the 1500 rpm nominal spin of the generator,which later causes the instability of the voltage and frequency.

Unexpected changes can also cause voltage instability. The generator has an excitation system that serves to amplify the active voltage field of the generator. On some generator systems, generator voltage settings have been equipped with.

The voltage stability and generator frequency of the Pico-hydropower plant are highly depend on the speed of the water turbine. In turbine hydroelectric power capacity, the rotation arrangement is performed by the power system stabilizer while the voltage regulation is performed by applying automatic voltage regulator.

In the generator voltage regulation system, the excitation system is a must to take into account the voltage stability of the generator. As the load increases, the excitation system 
generator serves to control the generator voltage by rearranging the input amount to reach a new equilibrium point.

Voltage stability may affect load performance such as electric motors and lighting, and temperature rise. Basically the stability of the voltage in the power system is the ability of the power system to restore the fixed voltage after an interruption occurs within a certain time. The voltage stability is expressed as the ability of the power system to maintain a fixed voltage along the bus in the system after an error occurs as the initial operating conditions.

The increasing problem in the micro-hydropower system is the fluctuations in frequency and unbalanced voltage profiles generated by generators with unequal loads on the customer side. This can trigger unfavourable effects on various electrical appliances [1].

The effect of the load side of the generator makes the voltage drop slowly under its nominal voltage. In this experiment, the generator is modeled on a Pico hydroelectric generator, when the generator is loaded, the voltage drops slowly and the pseudo generator power remains lit linearly.

If the load is increased to the installed power capacity of the generator, the voltage drops below its nominal voltage and the real power generated by the generator is no longer linear. In this study, the main driving generator used the turbine water simulator $1060 \mathrm{rpm}$. Installed generator capacity is $1 \mathrm{~kW} 400 \mathrm{Volt} 50 \mathrm{~Hz}$ and $1500 \mathrm{rpm}$. Volt d.c

In this study, the prime mover generator uses a $1060 \mathrm{rpm}$ turbine water simulator. The installed generating capacity is $1 \mathrm{~kW} 400 \mathrm{Volt} 50 \mathrm{~Hz}$ and $1500 \mathrm{rpm}$. The Volt d.c Generator field excitation voltage is obtained directly from the rectification result a full wave rectifier circuit and becomes the excitation field source of the generator field.

The purpose of this study is to obtain load characteristics against generator voltages due to the inability of water turbines to balance the nominal rotation of the generator on the Picohydropower plant.

\section{PICO-HYDROPOWER}

Pico hydro is a hydro power plant with maximum power output of up to $5 \mathrm{~kW}$. This measure of water power benefits in terms of cost, simplicity of various approaches in design and installation of the design, as compared to larger hydroelectric power plants. The latest innovations in Pico-hydro technology have made them a source of electrical energy even in some rural areas of the world. Because it is a versatile source of power, electricity can be produced by allowing standard electrical equipment. Some electrical devices that can be powered by Pico-hydro are light bulbs, radio, and television[2].

To provide electricity to off-grid areas in the country, the Pico hydroelectric is a very promising option. By utilizing the energy from the waterfall through the steep mountain is the water power. The water that flows is then converted into useful mechanical energy in a way like a water turbine works by using an alternator or generator. Then the mechanical power of the turbine can be converted into electricity.

Hydrokinetic methods of harvesting energy from the flow convert the kinetic energy of flow into mechanical energy by a machine that generates an electric current by a generator mounted on a shaft similar to a wind turbine. Hydrokinetic devices work with the greatest efficiency at locations where the water level is high and the current is relatively stable throughout the year, since the available power depends principally on the current velocity [3]. 


\subsection{Generator Excitation}

The main purpose of an excitation system generator is to supply a power source to the rotor field coil. The excitation system produces field currents and is controlled by automatic voltage regulators. This field flow control is important to ensure the generator is on at the appropriate voltage. It also controls the current value when the generator is connected to a large load. This will accept or provide the required reactive power level (kVAr). These are some factors for good running generator conditions.

The important issueregarding the combination of excitation system and automatic voltage regulator are as follow:

- Control the machine voltage accurately in response to slow power changes or reactive var request.

- $\quad$ Limit the magnitude of voltage visits due to unexpected load changes.

- Maintain steady-state stability.

- Ensure transient stability due to system faults.

\subsubsection{Excitation System for Generator}

Normally, to supply field current the DC generator is used and connected to the synchronous machine by its shaft. As for high-speed generators, a gearbox is used to reduce the exciter speed to its standard, around 700-1000 rpm.

It aims to avoid replacement problems with DC generators. In addition, the ring slip method is a common practice to feed exciter rotor output. This exciter is installed separately from the pilot plus. The overall dynamic performance of the system can be increased substantially by combining field coercion capability and additional stabilization signals.

\subsubsection{Self-Excitation System}

Self-Excitation Systems Equivalent schemes of self-excitation systems can be represented as series of inductance circuit and winding resistance and voltage source dependent on current circuit current motion as shown in Figure. 2. Self-excitation process consists of two stages. First, the charged capacitor is released through the excitation roll $\mathrm{L}_{\mathrm{f}}$. In the applied generator, the excitation winding parameters are $\mathrm{L}_{\mathrm{f}}=17 \mathrm{mH}$ and $\mathrm{R}_{\mathrm{f}}=2 \Omega$ [4].

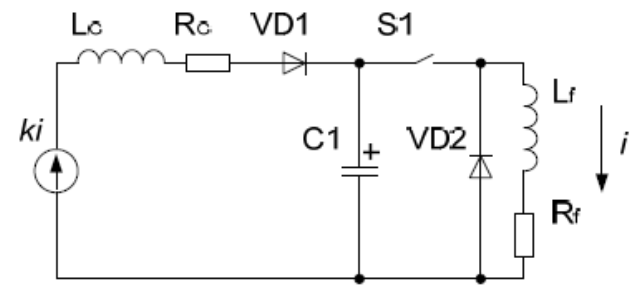

Fig. 1 The self-excitation system equivalent scheme[4]

This stage depends on circuit parameters and capacitor $C_{1}$ initial voltage $U_{c 1}$ :

$$
L_{f} \frac{d i}{d t}+\frac{1}{C_{1}} \int i d t-U_{c 1}-U_{C 1}=0,
$$

Where $C_{1}$ is capacity of capacitor $C_{1}$. 
At the second stage, the capacitor is used as a filter and further self-excitation depends on the rise of electromotive force connected with the rise of current. The scheme can be described as

$$
\left(L_{G}+L_{G}\right) \frac{d i}{d t}+i\left(R_{G}+R_{f}-k\right)+\frac{1}{C_{1}} \int i d t=0,
$$

The process is developing only if $k>\left(R_{G}+R_{f}\right)$. Indicator $k$ characterizes connection between the equivalent electromotive force of generator and current in excitation winding and it depends on the rotation speed of generator[4].

The self-excitation system of G1 sync generator with independent excitation is realized (Figure 2) with the $\mathrm{L}_{\mathrm{f}}$ excitation circuit connection to the stator phase output through a three phase controlled thyristor rectifier[5].

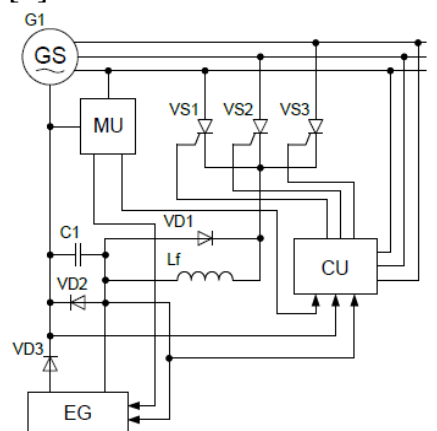

Fig. 2 The self-excitation system of synchronous generator with independent excitation[5].

\subsection{Power Quality} [6].

Power quality has become an increasing concern for utilities and their electrical customers

In the electric power system, each generator is equipped with a load frequency control (LFC) and an automatic voltage regulator (AVR) to maintain the system frequency and magnitude of the generator output voltage in the desired range when changes are observed in real/reactive [7].

Usually, there are two modes of operation on this plant, ie isolated mode and gridconnected mode. Under good mode, consumers who are fed by a micro power plant need continuous strength with good quality. One quality index is the frequency of the power system. Frequency drift is inevitable due to the imbalance between generation and load. To keep the frequency index within the allowable range, the control mechanism entitled load frequency control (LFC) increases [8].

This abnormal condition determines the voltage and current waveforms characterized by continuous disturbances including spectral content in wide frequency intervals (from 0-150 $\mathrm{kHz}$ ), with uniform behavior in both time and frequency[9].

\section{EXPERIMENT METHOD}

The installed power capacity of the generator is $1 \mathrm{kVA}, 400 \mathrm{Volt}, 50 \mathrm{~Hz}$ and $1500 \mathrm{rpm}$. In this simulation, the water turbine is rotated at $1800 \mathrm{rpm}$. To obtain the generator voltage curve, the excitation current of the generator is set at $350 \mathrm{~mA}$ and voltage 18 VDC. Figure 3. 
The Pico-hydropower plant 3-Phase-Generator Voltage Adjustment In the three-phase sync generator, the amount of off-load voltage generated depends on the speed of the revolution and the exciter voltage. The generator rotor is driven by a water turbine.

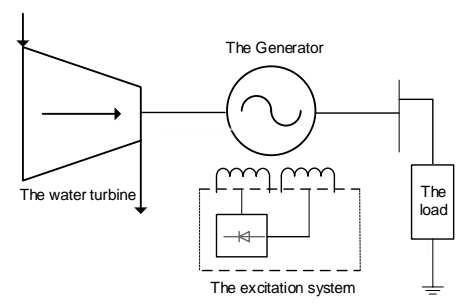

Fig. 3 The Pico-hydropower plant

\subsection{Experimental Result}

In the three-phase synchronous generator, the magnitude of the off-load voltage produced is dependent on the speed of revolution and the exciter voltage. The rotor of the generator is driven by the water turbine. The stationary magnetic field is induced in the winding rotor with the application of DC voltage.

The rotation of the rotor produces a rotating field for the stator, which induces three voltages in stator windings, $120^{\circ}$ from phase to each other, generator producing 3 phase voltage. The circuit as shown in the diagram of Figure. 4 is the adjustment of the connection and the 3-phase generator voltage.

Adjust the speed revolution of the pico-hydropower to $1500 \mathrm{rpm}$, using the valve control of flow rate. Adjust the exciter current 200 to $400 \mathrm{~mA}$ and keep it constant during this measurement.

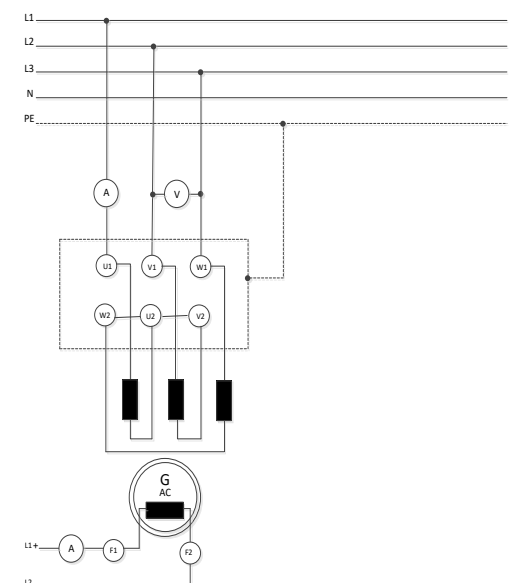

Fig. 4 Connection and voltage adjustment

In Table 1 shows the result of the measurement of the generator voltage based on the change of the excitation current in the no-load state. 
Table 1. Change of excitation current to generator voltage

\begin{tabular}{cccccc}
\hline $\mathrm{n}(\mathrm{rpm})$ & \multicolumn{5}{c}{1500} \\
\hline $\mathrm{I}_{\mathrm{Exc} .}(\mathrm{mA})$ & 200 & 250 & 300 & 250 & 400 \\
$\mathrm{~V}_{\text {Gen }}(\mathrm{V})$ & 255 & 310 & 355 & 400 & 445 \\
\hline
\end{tabular}

At $320 \mathrm{~mA}$ exciter current, the generator produces its nominal voltage of $380 \mathrm{~V}$ (when under no load). As the exciter current increases, the magnetic field in the rotor becomes larger. Thus, the generator consumes more energy and the revolution speed of the drive machine is produced. Figure. 5 shows the generator voltage curve generated based on the change in the excitation current of the generator.

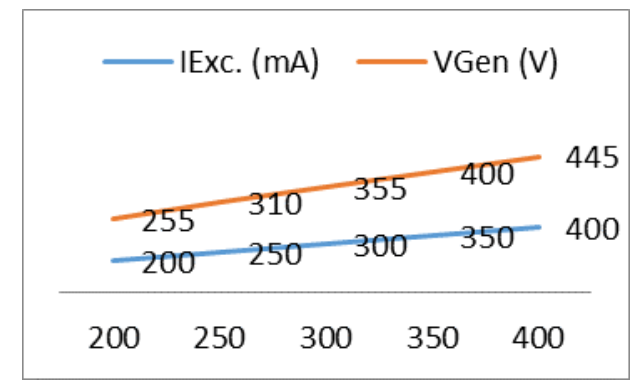

Fig. 5 The Curve of the generator voltage

\subsection{Load Characteristics of generator}

The voltage produced by dependent on the exciter current and the speed of revolution. The frequency of the generator voltage is proportional to the revolution speed.

$$
f(H z)=\frac{n(r p m) \cdot p}{60}
$$

Where=number of pole pairs $=2$

To be able to generate the usual mains frequency $50 \mathrm{~Hz}$, the generator must be driven at $1500 \mathrm{rpm}$. The magnitude of the generator voltage is adjusted by the exciter current.

Because of to the low revolution speed, the exciter coils of the salient-pole machine are packed tightly, as in DC machine. The rotor is also referred to as a pole spider; it has an amortises winding which is in the form of individual rods. At each end, short-circuit ring connect the rods together. The rotor is similar to a three-phase cage rotor asynchronous machine.

The circuit diagram is illustrated in Figure 6. Set the load to $100 \%$ and adjust the speed revolution of the Pico-hydropower to $1500 \mathrm{rpm}$, using the valve control of flow rate. 


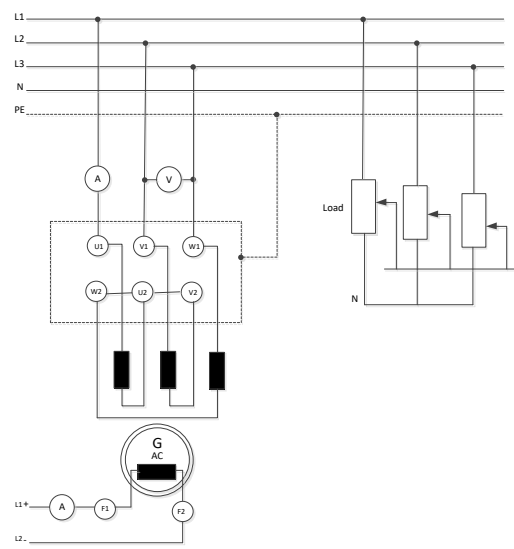

Fig. 6 Loading on the generator

Adjust the exciter current to $350 \mathrm{~mA}$ and keep this also constant during the measurements. Increase the loading on the generator by reducing the load. So that the values of current flow, as given in the Table. 2, are produced.

Table 2. Change the excitation current to the generator voltage with the load.

\begin{tabular}{lcccc}
\hline \multicolumn{1}{c}{$\mathrm{n}(\mathrm{rpm})$} & \multicolumn{4}{c}{1500} \\
$\mathrm{I}_{\text {Exc. }}(\mathrm{mA})$ & \multicolumn{5}{c}{350} \\
\hline $\mathrm{I}(\mathrm{mA})$ & 200 & 300 & 400 & 600 \\
$\mathrm{~V}_{\text {Gen }}(\mathrm{V})$ & 399 & 396 & 392 & 380 \\
$\mathrm{~S}(\mathrm{VA})$ & 138.1 & 205.5 & 271.3 & 394.4 \\
$\mathrm{~S}_{\text {Load }}(\mathrm{VA})$ & 414.3 & 616.5 & 813.9 & 1183.2 \\
\hline
\end{tabular}

When the generator loading at 414.3-1183.2 VA, the generator voltage decreases slowly from 399-380 Volts. Generic power generated by generator shows a linear increase of 138.1394.4 VA. If the generator load is raised to 1183.2 VA, voltage drop off rapidly. The apparent power produced shown, the curve of apparent power flatters as in shown Figure 7.

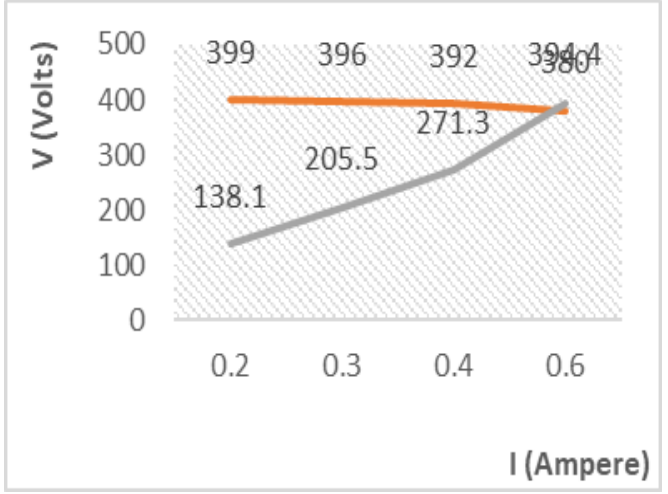

Fig. 7 The Load characteristics generator 


\section{Conclusions}

When under load, at $320 \mathrm{~mA}$ exciter current, the generator produces its nominal voltage of 380 Volts. As the exciter current increase, the magnetic field in the rotor becomes greater. Thus, the generator consumes more energy and the revolution speed of the drive machine is produced.

When the generator is loaded, the voltage falls slightly until the point the nominal apparent power is reached. If the load on the generator is further increased, the voltage drops off rapidly. The apparent power produced shows, initially a linear increase. As the load increase, the curve of apparent power flatters.

\section{ACKNOWLEDGEMENTS}

The authors would like to thank the P2M Unit, the Ministry of Research and Technology and Higher Education, and the Lhokseumawe State Polytechnic who provided support for this research.

\section{REFERENCES}

[1] N. A. N. W. I. N. Aung and A. Z. E. Ya, "Design of Electronic Load Controller By Using Combination Method for Micro-Hydro Power Plant," no. 6, pp. 6-12, 2015.

[2] H. Zainuddin, M. S. Yahaya, J. M. Lazi, M. F. M. Basar, and Z. Ibrahim, "Design and Development of Pico-hydro Generation System for Energy Storage Using Consuming Water Distributed to Houses," Water, vol. 3, no. 11, pp. 154-159, 2009.

[3] N. Zengin, F. Aslan, T. C. Artunç, M. E. Aktan, and Ö. F. Güney, "Design of Hydrokinetic Energy Generation System," CBU Int. Conf. Proc., vol. 4, p. 857, 2016.

[4] G. Zaleskis, I. Rankis, and M. Prieditis, "Self-Excitation System for Synchronous Generator," Electr. Control Commun. Eng., vol. 4, no. 1, 2013.

[5] G. Zaleskis and I. Rankis, "Capacitor activated self-excitation system of synchronous generator," Elektron. ir Elektrotechnika, vol. 123, no. 7, pp. 53-56, 2012.

[6] E. Series, "POWER QUALITY AND ENERGY EFFICIENCY IN LOW VOLTAGE ELECTRICAL POWER SYSTEM OF THE TECHNICAL UNIVERSITY OF GABROVO Krasimir Marinov Ivanov, Technical University of Gabrovo, Gabrovo, BULGARIA Georgi Tsonev Velev, Technical University of Gabrovo, Gabrov," no. 4, 2015.

[7] Ş. SÖNMEZ and S. AYASUN, "Effect of load increase and power system stabilizer on stability delay margin of a generator excitation control system," Turkish J. Electr. Eng. Comput. Sci., vol. 24, pp. 5183-5194, 2016.

[8] D. Qian, S. Tong, and X. Liu, "Load Frequency Control for Micro Hydro Power Plants by Sliding Mode and Model Order Reduction," Autom. - J. Control. Meas. Electron. Comput. Commun., vol. 56, no. 3, pp. 318-330, 2015.

[9] L. Alfieri, A. Bracale, and A. Larsson, New Power Quality Indices for the Assessment of Waveform Distortions from 0 to $150 \mathrm{kHz}$ in Power Systems with Renewable Generation and Modern Non-Linear Loads, vol. 10, no. 10. 2017. 